Gut, 1978, 19, 474-480

\title{
New insights into the classification and mechanisms of hereditary, chronic, non-haemolytic hyperbilirubinaemias
}

\author{
P. BERTHELOT AND D. DHUMEAUX
}

From the Unité de Recherches INSERM U-99, Hôpital Henri Mondor, 94010 Créteil, France

SUMMARY Gilbert's syndrome is typically associated with a deficiency in hepatic bilirubin UDPglucuronosyltransferase activity (B-GTA). The overproduction of bilirubin that is often found in this condition could be a fortuitous coincidence that leads to the unmasking of the disease, which otherwise often remains latent. Some cases of chronic unconjugated hyperbilirubinaemia could, however, be related to a defect in hepatic uptake, as reflected by alterations in BSP kinetics. Severe deficiencies of hepatic B-GTA exist in all types of Crigler-Najjar disease. An increased proportion of bilirubin monoglucuronide is always found in bile when a B-GTA deficiency is present. This observation strongly suggests a common biochemical defect in Gilbert's syndrome and in Crigler-Najjar disease, and thus renders the suggestion that the latter condition may be separated into two groups somewhat inappropriate. There is, however, no doubt that further knowledge of the conjugating enzyme, or enzymes, is required: such information may lead to the characterisation of several types of enzymic defects. Whereas little is new as far as the Dubin-Johnson syndrome is concerned, Rotor's syndrome can no longer be considered to be a variant of the former. The transport defect which is involved in most cases of Rotor's syndrome, if not in all, is an impairment of hepatic storage, thus distinguishing it from the impairment of excretion which is involved in the Dubin-Johnson syndrome. The distinct patterns of urinary coproporphyrin excretion, which were recently reported in DubinJohnson and Rotor's syndromes, offer additional evidence for a clear differentiation between these two entities.

Hereditary chronic hyperbilirubinaemias are made up of several, often confusing diseases. For some of them at least, however, recent improvement in either techniques or concepts has allowed a reappraisal of the mechanisms involved, and thus of their classification. Such a classification will be the aim of the present review, which will be restricted to those chronic hyperbilirubinaemias related specifically to the liver-that is, it will not be concerned with those cases explained solely by overproduction of bilirubin such as haemolysis.

\section{Gilbert's syndrome}

When Gilbert first described his syndrome, at the beginning of this century (Gilbert and Lereboullet, 1901), he mixed a number of diseases together. Thus, when he referred to 'acholuric' patients, dark urine was present in some of them. He also included several subjects with upper gastrointestinal bleeding and enlargement of either the liver or the spleen. From his post-mortem examinations, it becomes evident that also included in his series were individuals with gallstones and with cholangitis, and so on. Subsequently, it was agreed to consider as Gilbert's syndrome all cases of adults having chronic, mild, unconjugated hyperbilirubinaemia without overt haemolysis or structural liver disease.

The syndrome appears to be a constitutional disorder, probably inherited as an autosomal, dominant trait (Powell et al., 1967), although this is often far from evident in many cases. Its frequency seems high, as around $5 \%$ of the general population may be affected (Kornberg, 1942; Foulk et al., 1959). For obscure reasons, the jaundice usually does not appear before the age of 15 or 20 years. If one believes, however, that most cases reflect a deficiency of the enzyme which conjugates bilirubin, as will be discussed below, it seems likely that the probable regulation of this enzyme by steroid hormones may 
explain the role of puberty in unmasking the disease clinically. Such a hypothesis is consistent with the inhibition that various steroids exert on the conjugating enzyme in vitro (Adlard and Lathe, 1971). The increase in jaundice during fasting (Owens and Sherlock, 1973; Kirshenbaum et al., 1976), a situation which also involves complex endocrine changes, may perhaps be subject in part to a similar mechanism; too little is known, however, of the physiological regulation of the system of the hepatic glycosyltransferases for this proposal to be fully evaluated (Fevery et al., 1976). The course of this disease is essentially benign; thus attempts to influence it with phenobarbitone (Black and Sherlock, 1970) or other enzyme inducers (Orme et al., 1974) seem not justified as a long-term treatment, even though these substances have a dramatic effect on the jaundice itself.

The diagnosis of Gilbert's syndrome has long been made on the basis of the exclusion of other diseases, and has therefore depended on the extent of the investigations performed. At present, two different approaches to diagnosis may be emphasised. The first is based on the delayed plasma disappearance rate of exogenously injected bilirubin (Billing et al., 1964), as studied in more detail with trace amounts of ${ }^{14} \mathrm{C}$ or ${ }^{3} \mathrm{H}$-labelled bilirubin (Berk and Blaschke, 1972; Cobelli et al., 1975; Kirshenbaum et al., 1976). This latter procedure has also permitted the confirmation and measurement of the overproduction of bilirubin which is often associated with Gilbert's syndrome (Foulk et al., 1959; Powell et al., 1967; Berk and Blaschke, 1972; Metreau et al., 1974; Berk et al., 1976). Bilirubin kinetics are not, however, performed easily; in addition, they provide no information on the biochemical abnormalities which must be involved.

The second approach to diagnosis is related to the demonstration of markedly decreased bilirubinUDP-glucuronosyltransferase activity in the liver of patients with Gilbert's syndrome (Black and Billing, 1969). It apparently offers a satisfactory explanation for the unconjugated hyperbilirubinaemia. However, many difficulties persist, perhaps in part because this enzyme assay, studied in vitro (Van Roy and Heirwegh, 1968; Black et al., 1970; Heirwegh et al., 1973), may not reflect all situations encountered in vivo. There is no correlation between the activity as measured in vitro and the level of bilirubin in the serum (Black and Billing, 1969; Felsher et al., 1973; Metreau et al., 1974); because of the rather wide range in normal values, it remains somewhat artificial to fix their lowest level. Thus, for practical reasons-for example, low activities in small specimens-enzymic activity is usually assayed in a complete homogenate, which may contain inhibitors, and in the presence of detergents which can unmask enzymic sites lacking any physiological importance. Apart from the enzyme which is assayed, there may be a second enzymic system (Jansen et al., 1977) which would specifically involve the formation of bilirubin-diglucuronide. It must also be borne in mind that a deficiency in glucuronidation can be associated with other disorders. It can, for instance, be associated with a diminution in the hepatic uptake of bilirubin: such a diminution might result from the defective enzyme. It may be also associated with bilirubin overproduction, as already stated, which remains unexplained; we can offer the hypothesis that such a haemolysis or dyserythropoiesis, or both, which might represent no more than the extreme degree of the normal situation, may unmask Gilbert's syndrome when it is associated with a rather low activity of glucuronosyltransferase (Metreau et al., 1974). Finally, Gilbert's syndrome may even be associated with abnormalities which are apparently not related to bilirubin disposal, such as a high frequency of slow acetylators of drugs (Bircher et al., 1976), or a low hepatic clearance of tolbutamide (Carulli et al., 1976), a compound which does not undergo glucuronidation.

In spite of all these reservations, it remains clear that, when measured, bilirubin-UDP-glucuronosyltransferase activity was low in most adult patients with Gilbert's syndrome (Black and Billing, 1969; Felsher et al., 1973; Metreau et al., 1977). Its measurement also showed that the frequency of low activity in the general population $(3 \%$ in a personal series of 33 individuals) is not far from that found in unconjugated hyperbilirubinaemia in the absence of overt haemolysis.

Another point which deserves comment is the handling of bromsulphalein (BSP). It is usually normal in adults with unconjugated hyperbilirubinaemia (Dameshek and Singer, 1941); in our patients (Metreau et al., 1977) only three (three brothers) of 39 had a significant reduction in their plasma disappearance rate of BSP. This is apparently at variance with the experience of the group of $P$. Berk (Martin et al., 1976), who reported that the kinetics of BSP removal were abnormal in 11 of 26 patients with chronic unconjugated hyperbilirubinaemia. These authors pointed out, however, that some bias probably existed in the selection of their patients. The main question which arises from these findings is whether these patients, who had quite abnormal BSP kinetics but in whom glucuronosyltransferase was not measured, were affected by a disease which was distinct from that associated with, or related to, the enzyme deficiency. In this respect, it is of interest that among the three brothers who in our series had abnormal BSP kinetics, glucuronosyl- 
transferase activity could be measured in one and was normal. It is tempting to suggest that Gilbert's syndrome includes at least two distinct entities: the most common is associated with a reduced capacity to conjugate bilirubin, while the other could primarily reflect a defect in the uptake of various cholephilic anions by the hepatocyte.

\section{Crigler-Najjar disease}

This is an extremely rare condition, which appears very early in life. It is usually admitted that this disease is the consequence of a severe deficiency of the liver's ability to conjugate bilirubin. The chronic and marked resulting jaundice, due to unconjugated hyperbilirubinaemia, leads to a major potential complication in the newborn: kernicterus (bilirubin encephalopathy), causing severe cerebral damage and possible death. The reason for such a susceptibility of the 'immature' brain of the newborn remains unknown. Various factors which increase the risk of kernicterus can, however, be avoided, such as acidosis, hypoalbuminaemia, or the use of drugs able to increase the ratio of free/albuminbound bilirubin in the serum. This ratio, which unfortunately remains difficult to assay precisely, seems of much greater value in predicting kernicterus than the level of unconjugated bilirubin in the serum by itself.

Arias et al. (1969) suggested that Crigler-Najjar disease should be subdivided into two groups. Patients in group I were most severely affected: the serum bilirubin was 359 to $530 \mu \mathrm{mol} / 1$ ( 21 to 31 $\mathrm{mg} / 100 \mathrm{ml})$, the onset of jaundice was always at birth, kernicterus appeared in four out of the five patients described, and none responded to phenobarbitone therapy. In group II, the serum bilirubin ranged from 153 to $290 \mu \mathrm{mol} / \mathrm{l}(9$ to $17 \mathrm{mg} / 100 \mathrm{ml}$ ), the onset of jaundice was at birth in only seven out of the 11 patients, kernicterus was never observed, and phenobarbitone always effected a dramatic diminution in the jaundice. When measured, UDP glucuronosyltransferase activity with bilirubin as substrate was zero or near zero in all patients, whether of group I or II. The conjugation defect seemed to be transmitted as an autosomal recessive character in group I, and as an autosomal dominant character in group II.

There are, however, at least three arguments which suggest that such separation is difficult and that links may exist between all three varieties of bilirubin conjugating defects-namely, CriglerNajjar disease group I, Crigler-Najjar disease group II, and Gilbert's syndrome. The first argument is that clear-cut differences in the modes of inheritance are questionable (Kreek and Sleisenger, 1968;
Hunter et al., 1973). Secondly, there are a very few cases of Crigler-Najjar disease described in adults (Gollan et al., 1975), including a personal one (Fevery, Bouvry and Berthelot, unpublished observation) in whom the age, the absence of kernicterus, and a serum bilirubin level of about $256 \mu \mathrm{mol} / \mathrm{l}$ (15 $\mathrm{mg} / 100 \mathrm{ml}$ ) strongly suggested that the patient belonged to group II; there was, however, no response to phenobarbitone. Thirdly, analysis of the biliary bilirubin composition (Fevery et al., 1977) showed that the proportion of bilirubin monoconjugate increased progressively from controls to patients with Gilbert's syndrome, patients with Crigler-Najjar disease group II, and, finally, group I. This strongly suggests that a common biochemical defect, of increasing severity, may lie at the basis of all these types of jaundice.

\section{Dubin-Johnson syndrome}

Since it was first described (Dubin and Johnson, 1954; Sprinz and Nelson, 1954), this disorder has been shown to be a chronic, or more often intermittent, benign, familial, idiopathic jaundice which is related to a defect in canalicular excretion. This defect concerns a number of organic molecules, such as bilirubin, cholephilic dyes, cholecystographic agents, and porphyrins (Shani et al., 1970b) and has also been found in the mutant Corriedale sheep (Cornelius et al., 1965). In both sheep and man, however, the biliary transport of bile acids remains normal, thus supporting the existence of at least two distinct excretory pathways for organic anions. Serum bilirubin is predominantly conjugated; however, for reasons which are unclear, significant amounts of unconjugated bilirubin may be present. Deposits of a dark pigment, thought to be melanin (Bynum, 1957; Caroli et al., 1965), are found within the liver cell. This liver pigmentation varies in intensity from one patient to the other, and transiently disappears during and after acute viral hepatitis (Varma et al., 1970; Ware et al., 1972). In Israel, the Dubin-Johnson syndrome is associated in a considerable number of patients with a deficiency in clotting factor VII (Shani et al., 1970b); this observation has not been explained. The mode of inheritance is autosomal, recessive (Shani et al., 1970a; Wolkoff et al., 1973). The disease is slightly more common in males; in females, pregnancy or oral contraceptives can unmask the disorder by converting a mild pre-existing, conjugated hyperbilirubinaemia into overt jaundice (Cohen et al., 1972).

The kinetics of BSP clearly confirm the excretory defect. Whereas the relative storage capacity (S) is always normal, the transport maximum (Tm) is 
near zero (Shani et al., 1970a). Of a greater practical value, however, is the study of the plasma disappearance curve after a single injection of the dye: (1) the first slope $K_{1}$ is normal, or only slightly reduced (Chevrel et al., 1969), which is quite unusual in the presence of conjugated hyperbilirubinaemia, and (2) after 45 minutes of injection, a secondary rise in concentration of the dye occurs in the plasma. This rise involves a reflux of conjugated BSP, as shown by chromatography (Charbonnier and Brisbois, 1960; Mandema et al., 1960; Abe and Okuda, 1975), and does not exist when dyes which are not conjugated by the liver, such as dibromsulphalein or indocyanine green, are used (Erlinger et al., 1973). These findings suggest that the reentry of BSP into the plasma is related to its conjugation, the conjugated BSP having less affinity than the parent compound for binding to endoplasmic proteins.

Urinary coproporphyrins abnormalities are a most interesting finding in the Dubin-Johnson syndrome (Ben-Ezzer et al., 1971; Wolkoff et al., 1973; Kondo et al., 1976). The excretion of coproporphyrin $I$ is markedly increased, probably as a result of the defect in its biliary excretion, and is in contrast with the decrease in urinary coproporphyrin III. The consequence of both these changes is a normal, or slightly increased, urinary excretion of total coproporphyrins, with a marked increase in the ratio of isomer I to total coproporphyrins. Values intermediate between those obtained in patients and in normal subjects may be found in phenotypically normal parents or children of the patients (Wolkoff et al., 1973). There is no definite explanation for the decrease in the excretion of isomer III in urine, although it could be due to a reduced production of isomer III secondary to a defect or inhibition of the liver uroporphyrinogen III cosynthetase (Ben-Ezzer et al., 1971). Such an abnormality, if it existed, could yield a diminished synthesis of heme protein which may play a role in the excretory process in the liver (Wolkoff et al., 1973).

Administration of phenobarbitone to patients with the Dubin-Johnson syndrome generally results in a diminution of jaundice and improvement of the Tm of BSP (Shani et al., 1974). However, these effects are much too moderate to be of any therapeutic value, and their precise mechanism remains to be explained.

\section{Rotor's syndrome: uptake and storage disease}

The disorder described by Rotor et al. (1948) is a benign, familial, chronic or fluctuating, predominantly conjugated hyperbilirubinaemia without liver pigmentation. It is transmitted as an autosomal recessive character (Wolkoff et al., 1976). For a number of years, Rotor's syndrome has been considered as a variant of the Dubin-Johnson syndrome and related to an excretory defect. Among the arguments favouring this view was the report of two patients in the same family with the Dubin-Johnson syndrome, whereas a third had a Rotor's syndrome (Arias, 1961). In the recent years, however, a few patients were described who resembled those having Rotor's syndrome, but in whom jaundice was attributable to a defect in the hepatic uptake and storage of organic anions, as assessed by the kinetics of cholephilic dyes (Hadchouel et al., 1971; Dhumeaux and Berthelot, 1975). As there were only scarce and conflicting data of dye kinetics (Arias, 1961; Dollinger and Brandborg, 1967; Namihisa et al., 1973) in Rotor's syndrome at that time, similarities between this syndrome and the uptake and storage disease were emphasised (Dhumeaux and Berthelot, 1975). The probable identity between both conditions was recently confirmed, when Wolpert et al. (1977) investigated the kinetics of BSP in patients who had earlier been described as suffering from Rotor's syndrome. In these patients, the first slope of the plasma disappearance curve of the dye was impaired and no secondary rise was observed; the S of BSP was dramatically reduced. Their Tm was affected to a lesser extent, possibly as a result of the uptake and storage defect. Abnormalities in $K_{1}, S$, and $T m$ were found for unconjugated dyes as well as for BSP (Namihisa, 1976; Delage et al., 1977). All these findings suggest that most, if not all, patients with Rotor's syndrome suffer from a primary disorder of uptake and storage of bilirubin and therefore differ from those having a DubinJohnson syndrome. Such a distinction is further supported by the different patterns of excretion of urinary coproporphyrins. Urinary total coproporphyrin excretion is much higher in Rotor's syndrome than in that of Dubin-Johnson, and is the resuit of an increased excretion of isomer I and, to a lesser extent, of isomer III (Wolkoff et al., 1976). The ratio of isomer I to total coproporphyrins is increased, but not as much as in the Dubin-Johnson syndrome (Wolkoff et al., 1976). Finally, the changes observed in urinary coproporphyrin excretion in Rotor's syndrome are similar to those observed in any hepatobiliary disease (Ben-Ezzer et al., 1971) and may be simply explained by a shift from the biliary to the urinary route of excretion.

It remains somewhat surprising that a disease affecting liver uptake and storage of bilirubin leads to a hyperbilirubinaemia which, in large part, consists of conjugated bilirubin. A probable explanation is an increase in the liver to plasma reflux related to 
Table Main features of the different types of hereditary, chronic, non-haemolytic hyperbilirubinaemias

\begin{tabular}{|c|c|c|c|c|}
\hline & & Uptake and storage defect* & $\begin{array}{l}\text { Impairment of } \\
\text { bilirubin conjugation }\end{array}$ & Excretory (canalicular) defect $\dagger$ \\
\hline \multicolumn{2}{|c|}{ Current denomination } & Rotor's syndrome & $\begin{array}{l}\text { Gilbert's syndrome (GS) } \\
\text { and Crigler-Najjar disease } \\
\text { (CND) }\end{array}$ & Dubin-Johnson syndrome \\
\hline \multicolumn{2}{|c|}{$\begin{array}{l}\text { Animal model } \\
\text { Mode of transmission }\end{array}$} & $\begin{array}{l}\text { Mutant Southdown sheep } \\
\text { Recessive }\end{array}$ & $\begin{array}{l}\text { Gunn rat } \\
\text { Dominant for GS; } \\
\text { uncertain for CND }\end{array}$ & $\begin{array}{l}\text { Mutant Corriedale sheep } \\
\text { Recessive }\end{array}$ \\
\hline \multirow{2}{*}{\multicolumn{2}{|c|}{$\begin{array}{l}\text { Type of hyperbilirubinaemia } \\
\text { Bilirubin UDP-glucuronosyltransferase } \\
\text { activity } \\
\text { Bromsulphalein } \int K_{1} \\
\text { (BSP) }\end{array}$}} & $\begin{array}{l}\text { Conjugated and unconjugated } \\
\text { Normal }\end{array}$ & Unconjugated & $\begin{array}{l}\text { Conjugated and unconjugated } \\
\text { Normal }\end{array}$ \\
\hline & & $\downarrow \downarrow$ & Normal & $\begin{array}{l}\text { Normal, followed by } \\
\text { secondary rise }\end{array}$ \\
\hline & & $\downarrow \downarrow$ & $?$ & $\begin{array}{l}\text { Normal } \\
\downarrow \downarrow\end{array}$ \\
\hline $\begin{array}{l}\text { Urinary } \\
\text { coproporphyrins }\end{array}$ & $\left\{\begin{array}{l}\text { Total } \\
\text { Isomer I over total }\end{array}\right.$ & $\uparrow \uparrow$ & $\begin{array}{l}\text { Normal } \\
\text { Normal }\end{array}$ & $\begin{array}{l}\text { Normal or slightly } \uparrow \\
\uparrow \uparrow\end{array}$ \\
\hline
\end{tabular}

*Uptake and storage defects probably include several distinct entities. The most frequent type, now considered as being Rotor's syndrome, is that depicted in this table. Another one seems to exist (Métreau et al., 1977), which is characterised by entirely unconjugated hyperbilirubinaemia, normal bilirubin UDP-glucuronosyltransferase activity, and marked reduction in the $K_{1}$ and S of BSP.

†A similar disorder of canalicular excretion, not however associated with liver pigmentation and therefore differing from the Dubin-Johnson syndrome, has also been described (Arias, 1961).

the disease itself that is, a diminution in the intrahepatic binding of bilirubin. Such a reflux of conjugated bilirubin could be demonstrated with the use of ${ }^{14} \mathrm{C}$-labelled bilirubin in the mutant Southdown sheep, which also suffers from a similar impairment of uptake and storage (Cornelius and Gronwall, 1968; Mia et al., 1970). It is of interest that the intrahepatic content of ligandin seems to be normal in this animal (Arias, 1972), thus suggesting that this protein is not obligatorily involved in the pathogenesis of the disorder. This is also supported by the fact that phenobarbitone, which among many other actions increases the hepatic content of ligandin (Arias, 1972), influenced neither serum bilirubin, nor BSP $K_{1}$ when given to three patients (Delage and Dhumeaux, unpublished observations).

\section{Concluding remarks}

Considerable improvement has recently been achieved in defining the localisation of the hepatic defect involved in the various chronic, hereditary, non-haemolytic, hyperbilirubinaemias (Table). This has, for instance, allowed us to reconsider Rotor's syndrome, which in most cases appears as an uptake and storage disease, whereas for years it was considered to be a variant of the Dubin-Johnson syndrome - that is, an excretory defect. Furthermore, it has also allowed us to consider that a deficiency in bilirubin conjugation may explain most cases of unconjugated, chronic hyperbilirubinaemia in the adult in the absence of overt haemolysis. However, apart from this latter example, too little is known of the biochemical basis of the different types of hereditary hyperbilirubinaemias. Until more information is available, it will remain difficult to eliminate the heterogeneity which still exists among many of the various syndromes which have been described in the present review.

We wish to thank Dr John Chapman for careful assistance in reviewing the manuscript, and Mrs M. Tassier for its preparation.

\section{References}

Abe, H., and Okuda, K. (1975). Biliary excretion of conjugated sulfobromophthalein (BSP) in constitutional conjugated hyperbilirubinemias. Digestion, 13, 272-283.

Adlard, B. P. F., and Lathe, G. H. (1971). Specificity of the effects of steroids on bilirubin glucuronide transport by liver slice. Biochimica et Biophysica Acta, 237, 132-134.

Arias, I. M. (1961). Studies of chronic familial non-hemolytic jaundice with conjugated bilirubin in the serum with and without an unidentified pigment in the liver cells. American Journal of Medicine, 31, 510-518.

Arias, I. M. (1972). Transfer of bilirubin from blood to bile. Seminars in Hematology, 9, 55-70.

Arias, I. M., Gartner, L. M., Cohen, M., Ben-Ezzer, J., and Levi, A. J. (1969). Chronic nonhemolytic unconjugated hyperbilirubinemia with glucuronyl transferase deficiency. Clinical, biochemical, pharmacologic and genetic evidence for heterogeneity. American Journal of Medicine, 47, 395409.

Ben-Ezzer, J., Rimington, C., Shani, M., Seligsohn, U., Sheba, C., and Szeinberg, A. (1971). Abnormal excretion of the isomers of urinary coproporphyrin by patients with Dubin-Johnson syndrome in Israel. Clinical Science, 40, 17-30.

Berk, P. D., and Blaschke, T. F. (1972). Detection of Gilbert's syndrome in patients with hemolysis. A method using radioactive chromium. Annals of Internal Medicine, 77, 527-531.

Berk, P. D., Blaschke, T. F., Scharschmidt, B. F., Waggoner, J. G., and Berlin, N. I. (1976). A new approach to quanti- 
tation of the various sources of bilirubin in man. Journal of Laboratory and Clinical Medicine, 87, 767-780.

Billing, B. H., Williams, R., and Richards, T. G. (1964). Defects in hepatic transport of bilirubin in congenital hyperbilirubinaemia: an analysis of plasma bilirubin disappearance curves. Clinical Science, 27, 245-257.

Bircher, J., Platzer, R., Kupfer, A., and Preisig, R. (1976). Pharmacogenetic aspects of Gilbert's syndrome. Gastroenterology, 71, 896. (Abstract).

Black, M., and Billing, B. H. (1969). Hepatic bilirubin UDPglucuronyl transferase activity in liver disease and Gilbert's syndrome. New England Journal of Medicine, 280, 12661271.

Black, M., Billing, B. H., and Heirwegh, K. P. M. (1970). Determination of bilirubin UDP-glucuronyl transferase activity in needle-biopsy specimens of human liver. Clinica Chimica Acta, 29, 27-35.

Black, M., and Sherlock, S. (1970). Treatment of Gilbert's syndrome with phenobarbitone. Lancet, 1, 1359-1362.

Bynum, W. T. (1957). Mavero-hepatic icterus (black liver jaundice). Gastroenterology, 33, 97-103.

Caroli, J., Julien, C., and Pousset, J.-L. (1965). La maladie de Dubin-Johnson, mélanose hépatique. Evolution des idées concernant la nature mélanique du pigment intra-hépatique et contribution nouvelle à propos d'un cas avec mélanurie. Revue Médico-Chirurgicale des Maladies du Foie, de la Rate et du Pancréas, 40, 133-158.

Carulli, N., Ponz De Leon, M., Mauro, E., Manenti, F., and Ferrari, A. (1976). Alteration of drug metabolism in Gilbert's syndrome. Gut, 17, 581-587.

Charbonnier, A., and Brisbois, P. (1960). Etude chromatographique de la B.S.P. au cours de l'épreuve clinique d'épuration plasmatique de ce colorant. Revue Internationale d'Hépatologie, 10, 1163-1213.

Chevrel, B., Lemonnier, F., and Caroli, J. (1969). Pente d'épuration ascendante de la B.S.P. Signification diagnostique et physiopathologique. Presse Médicale, 77, 19351938.

Cobelli, C., Frezza, M., and Tiribelli, C. (1975). Modeling, identification and parameter estimation of bilirubin kinetics in normal, hemolytic and Gilbert's state. Computers and Biochemical Research, 8, 522-537.

Cohen, L., Lewis, C., and Arias, I. M. (1972). Pregnancy, oral contraceptives, and chronic familial jaundice with predominantly conjugated hyperbilirubinemia (DubinJohnson syndrome). Gastroenterology, 62, 1182-1190.

Cornelius, C. E., Arias, I. M., and Osburn, B. I. (1965). Hepatic pigmentation with photosensitivity: a syndrome in Corriedale sheep resembling Dubin-Johnson syndrome in man. Journal of the American Veterinary Medical Association, 146, 709-713.

Cornelius, C. E., and Gronwall, R. R. (1968). Congenital photosensitivity and hyperbilirubinemia in Southdown sheep in the United States. Journal of the American Veterinary Medical Association, 29, 291-295.

Dameshek, W., and Singer, K. (1941). Familial nonhemolytic jaundice. Constitutional hepatic dysfunction with indirect Van den Bergh reaction. Archives of Internal Medicine, 67, 259-285.

Delage, Y., Saigot, T., Hadchouel, P., Touboul, J. P., Lévy, V. G., and Dhumeaux, D. (1977). Rotor's syndrome: evidence for an impairment of hepatic uptake and storage of cholephilic organic anions. Digestion, 15, 228-229. (Abstract).

Dhumeaux, D., and Berthelot, P. (1975). Chronic hyperbilirubinemia associated with hepatic uptake and storage impairment. A new syndrome resembling that of the mutant Southdown sheep. Gastroenterology, 69, 988-993.

Dollinger, M. R., and Brandborg, L. L. (1967). Late elevation in serum bromsulfalein in Dubin-Johnson syndrome.
A comparative case study. American Journal of Digestive Diseases, 12, 413-417.

Dubin, I. N., and Johnson, F. B. (1954). Chronic idiopathic jaundice with unidentified pigment in liver cells. A new clinicopathologic entity with a report of 12 cases. Medicine (Balt.), 33, 155-197.

Erlinger, S., Dhumeaux, D., Desjeux, J. F., and Benhamou, J. P. (1973). Hepatic handling of unconjugated dyes in the Dubin-Johnson syndrome. Gastroenterology, 64, 106-110.

Felsher, B. F., Craig, J. R., and Carpio, N. (1973). Hepatic bilirubin glucuronidation in Gilbert's syndrome. Journal of Laboratory and Clinical Medicine, 81, 829-837.

Fevery, J., Blanckaert, N., Heirwegh, K. P. M., and De Groote, J. (1976). Bilirubin conjugates: formation and detection. In Progress in Liver Diseases, Vol. 5, pp. 183-214. Edited by H. Popper and F. Schaffner. Grune and Stratton: New York.

Fevery, J., Blanckaert, N., Heirwegh, K. P. M., Préaux, A. M., and Berthelot, P. (1977). Unconjugated bilirubin and an increased proportion of bilirubin monoconjugates in the bile of patients with Gilbert's syndrome and CriglerNajjar disease. Journal of Clinical Investigation, 60, 970-979.

Foulk, W. T., Butt, H. R., Owen, C. A., Jr, Whitcomb, F. F., Jr, and Mason, H. L. (1959). Constitutional hepatic dysfunction (Gilbert's disease): its natural history and related syndromes. Medicine (Balt.), 38, 25-46.

Gilbert, C., and Lereboullet, P. (1901). La cholémie simple familiale. Semaine Médicale, 21, 241-243.

Gollan, J. L., Huang, S. N., Billing, B. H., and Sherlock, S. (1975). Prolonged survival in three brothers with severe type 2 Crigler-Najjar syndrome. Ultrastructural and metabolic studies. Gastroenterology, 68, 1543-1555.

Hadchouel, P., Charbonnier, A., Lageron, A., Lemonnier, F., Rautureau, M., Scotto, J., and Caroli, J. (1971). A propos d'une nouvelle forme d'ictère chronique idiopathique. Hypothèse physio-pathologique. Revue Médico-Chirurgicale des Maladies du Foie, de la Rate et du Pancréas, 46, 6168.

Heirwegh, K. P. M., Meuwissen, J. A. T. P., and Fevery, J. (1973). Critique of the assay and significance of bilirubin conjugation. Advances in Clinical Chemistry, 16, 239-289.

Hunter, J. O., Thompson, R. P. H., Dunn, P. M., and Williams, R. (1973). Inheritance of type 2 Crigler-Najjar hyperbilirubinaemia. Gut, 14, 46-49.

Jansen, P. L. M., Chowdhury, J. R., Fischberg, E. B., and Arias, I. M. (1977). Enzymatic conversion of bilirubin monoglucuronide to diglucuronide by rat liver plasma membranes. Journal of Biological Chemistry, 252, 27102716.

Kirshenbaum, G., Shames, D. M., and Schmid, R. (1976). An expanded model of bilirubin kinetics: effect of feeding, fasting, and phenobarbital in Gilbert's syndrome. Journal of Pharmacokinetics and Biopharmaceutics, 4, 115-155.

Kondo, T., Kuchiba, K., and Shimizu, Y. (1976). Coproporphyrin isomers in Dubin-Johnson syndrome. Gastroenterology, 70, 1117-1120.

Kornberg, A. (1942). Latent liver disease in persons recovered from catarrhal jaundice and in otherwise normal medical students as revealed by the bilirubin excretion test. Journal of Clinical Investigation, 21, 299-308.

Kreek, M. J., and Sleisenger, M. H. (1968). Reduction of serum-unconjugated-bilirubin with phenobarbitone in adult congenital non-haemolytic unconjugated hyperbilirubinaemia. Lancet, 2, 73-78.

Mandema, E., De Fraiture, W. H., Nieweg, H. O., and Arends, A. (1960). Familial chronic idiopathic jaundice (Dubin-Sprinz disease), with a note on bromsulphalein metabolism in this disease. American Journal of Medicine, 28, $42-50$.

Martin, J. F., Vierling, J. M., Wolkoff, A. W., Scharschmidt, 
B. F., Vergalla, J., Waggoner, J. G., and Berk, P. D. (1976). Abnormal hepatic transport of indocyanine green in Gilbert's syndrome. Gastroenterology, 70, 385-391.

Metreau, J. M., Dhumeaux, D., Gisselbrecht, C., Preaux, A. M., and Berthelot, P. (1977). Constitutional unconjugated hyperbilirubinaemia (letter). Lancet, 1, 1319.

Metreau, J. M., Roudot, F., Preaux, A. M., Dhumeaux, D., and Berthelot, P. (1974). Dyserythropoiesis or hemolysis: a necessary condition for disclosing Gilbert's disease? Digestion, 10, 315. (Abstract.)

Mia, A. S., Gronwall, R. R., and Cornelius, C. E. (1970). Unconjugated and conjugated bilirubin transport in normal and mutant Corriedale sheep with Dubin-Johnson syndrome. Proceedings of the Society for Experimental Biology and Medicine, 135, 33-37.

Namihisa, T. (1976). Chronic benign hyperbilirubinemia (letter). Gastroenterology, 70, 636.

Namihisa, T., Yamaguchi, K., and Nambu, M. (1973). The constitutional conjugated hyperbilirubinemia (DubinJohnson syndrome and Rotor's type of hyperbilirubinemia). New definitions based on studies of transport with indocyanine green and bromsulphthalein. Gastroenterologica Japonica, 8, 217-223.

Orme, M. L'E., Davies, L., and Breckenridge, A. (1974). Increased glucuronidation of bilirubin in man and rat by administration of antipyrine (phenazone). Clinical Science and Molecular Medicine, 46, 511-518.

Owens, D., and Sherlock, S. (1973). Diagnosis of Gilbert's syndrome: role of reduced caloric intake test. British Medical Journal, 3, 559-563.

Powell, L. W., Hemingway, E., Billing, B. H., and Sherlock, S. (1967). Idiopathic unconjugated hyperbilirubinemia (Gilbert's syndrome). A study of 42 families. New England Journal of Medicine, 277, 1108-1112.

Rotor, A. B., Manahan, L., and Florentin, A. (1948). Familial non-hemolytic jaundice with direct Van den Bergh reaction. Acta Medica Philippina, 5, 37-49.
Shani, M., Gilon, E., Ben-Ezzer, J., and Sheba, C. (1970a). Sulfobromophthalein tolerance test in patients with DubinJohnson syndrome and their relatives. Gastroenterology, $59,842-847$.

Shani, M., Seligsohn, U., Gilon, E., Sheba, C., and Adam, A. (1970b). Dubin-Johnson syndrome in Israel. I. Clinical, laboratory, and genetic aspects of 101 cases. Quarterly Journal of Medicine, 39, 549-567.

Shani, M., Seligsohn, U., and Ben-Ezzer, J. (1974). Effect of phenobarbital on liver functions in patients with DubinJohnson syndrome. Gastroenterology, 67, 303-308.

Sprinz, H., and Nelson, R. S. (1954). Persistent nonhemolytic hyperbilirubinemia associated with lipochromelike pigment in liver cells: report of four cases. Annals of Internal Medicine, 41, 952-962.

Van Roy, F. P., and Heirwegh, K. P. M. (1968). Determination of bilirubin glucuronide and assay of glucuronyltransferase with bilirubin as acceptor. Biochemical Journal, 107, 507-518.

Varma, R. R., Grainger, J. M., and Scheuer, P. J. (1970). A case of the Dubin-Johnson syndrome complicated by acute hepatitis. Gut, 11, 817-821.

Ware, A. J., Eigenbrodt, E. H., Shorey, J., and Combes, B. (1972). Viral hepatitis complicating the Dubin-Johnson syndrome. Gastroenterology, 63, 331-339.

Wolkoff, A. W., Cohen, L. E., and Arias, I. M. (1973). Inheritance of the Dubin-Johnson syndrome. New England Journal of Medicine, 288, 113-117.

Wolkoff, A. W., Wolpert, E., Pascasio, F. N., and Arias, I. M. (1976). Rotor's syndrome. A distinct inheritable pathophysiologic entity. American Journal of Medicine, 60, 173179.

Wolpert, E., Pascasio, F. M., Wolkoff, A. W., and Arias, I. M. (1977). Abnormal sulfobromophthalein metabolism in Rotor's syndrome and obligate heterozygotes. New England Journal of Medicine, 296, 1099-1101. 